Ambiente \& Água - An Interdisciplinary Journal of Applied Science
ISSN 1980-993X - doi:10.4136/1980-993X
www.ambi-agua.net
E-mail: ambi-agua@agro.unitau.br

\title{
Reflexos das alterações no Código Florestal Brasileiro em Áreas de Preservação Permanentes de duas propriedades rurais em Itu e Sarapuí, SP
}

doi: 10.4136/ambi-agua.1354

Received: 03 Apr. 2014; Accepted: 27 Jun. 2014

\author{
Luiz Carlos de Faria ; Francisco Carlos Adriano Júnior; \\ Kelly Cristina Tonello; Roberta de Oliveira Averna Valente \\ Universidade Federal de São Carlos (UFSCAR), Sorocaba, SP, Brasil \\ Departamento de Ciências Ambientais \\ *Autor correspondente: e-mail: lcfaria@ufscar.br, \\ francisco_sliver@hotmail.com, kellytonello@ufscar.br, \\ roavalen@ufscar.br
}

\section{RESUMO}

Discussões sobre a legislação florestal brasileira se intensificaram nos últimos anos e conduziram a edição de um novo Código Florestal Brasileiro. O objetivo desse trabalho foi realizar um estudo comparativo das Áreas de Preservação Permanente (APPs) de propriedades rurais localizadas em Itu e Sarapuí, SP, conforme a Lei Federal $n^{\circ} 12.651 / 12$, Lei Federal $\mathrm{n}^{\circ}$ 4.771/65 e as Resoluções CONAMA 302 e 303. Delimitou-se as áreas de APPs utilizandose cartas topográficas do Instituto de Geografia e Cartografia (IGC) em escala de 1:10.000, ortofoto georeferenciada do ano 2005, em escala de 1:30.000, e verificações de campo. Os resultados mostraram que houve redução nas áreas de APPs nas duas propriedades, sendo de $20,97 \%$ para $17,81 \%$ da área total do imóvel para a propriedade de Itu e de 23,16\% para $8,11 \%$ para a propriedade de Sarapuí. As recentes modificações no Código Florestal Brasileiro reduziram as APPs de alguns elementos da paisagem nas duas propriedades avaliadas. Também houve fragmentação da APP no entorno de cursos d'água em uma das propriedades. De modo geral, os fatores que mais contribuíram para esse resultado foram a diminuição na largura estabelecida para APPs de cursos de água em áreas consolidadas, a dispensa de estabelecimento de APP em nascentes intermitentes e no entorno de lagos artificiais com superfície inferior a um hectare.

Palavras-chave: política e legislação ambiental, propriedades rurais, adequação ambiental.

\section{Reflections of changes in the Brazilian Forest Law in Permanent Preservation Areas on two farms in Itu and Sarapuí, SP}

\begin{abstract}
Discussions of Brazilian forest legislation have intensified in recent years and have led to the publication of a new Brazilian Forest Code. This study was a comparative analysis of Permanent Preservation Areas (PPAs) of farms located in Itu and Sarapuí, SP, according to Federal Law No. 12.651/12, Federal Law No. 4.771/65 and CONAMA Resolutions 302 and 303. We outlined the PPAs using topographic maps of the Institute of Geography and
\end{abstract}


Cartography (IGC) in scale of 1:10,000, geo-referenced ortho-photo of 2005, scale 1:30,000, and field checks. The results showed that there was a reduction in the PPAs in the two properties, which was $20.97 \%$ to $17.81 \%$ of the total area of the property in Itu and $23.16 \%$ to $8.11 \%$ of the property in Sarapuí. The recent changes in the Brazilian Forest Code reduced PPAs in some landscape elements of the two properties. Also, there was fragmentation of a PPA in the vicinity of water courses on one of the properties. In general, the factors that contributed to this were the decrease in the width set for PPAs of water courses in consolidated areas, the exclusion of PPAs in intermittent springs and around ponds with surface areas smaller than one hectare.

Keywords: environmental policy and legislation, rural properties, environmental suitability.

\section{INTRODUÇÃO}

O Código Florestal Brasileiro é umas das principais leis ambientais do Brasil. Sua primeira versão foi editada em 1934, através do Decreto Federal n 23.793 (Brasil, 1934). Com tendências preservacionistas em relação ao patrimônio florestal nacional, um avanço para a época, nele já constava uma conceituação de áreas de elevada importância dentro dos ecossistemas naturais (Borges et al., 2011). O Decreto Federal de 1934 foi revogado pela Lei Federal $n^{\circ} 4.771 / 65$ ainda durante o Regime Militar. Denominando de Novo Código Florestal, essa Lei foi considerada mais rígida que o texto anterior (Brasil, 1965). O Novo Código Florestal utilizou-se de medidas de comando e controle através da criação da Área de Preservação Permanente (APP) e da Área de Reserva Legal (RL), como forma de garantir a preservação ambiental e o uso sustentado dos recursos naturais em propriedades rurais (Garcia, 2012; Brasil, 1965). Na Lei Federal n4.771/65 foi introduzido o conceito primitivo de florestas protetoras, que acabou por se desenvolver nas chamadas Áreas de Preservação Permanente (APP), tendo então sua definição consagrada, sem margens para interpretações equivocadas. Segundo a Lei Federal $n^{\circ} 4.771 / 65$, são consideradas APPs as áreas no entorno dos cursos d'água, de nascentes perenes e intermitentes, e dos chamados "olhos d'água", definidos como afloramentos naturais de água, dentre outras modalidades. Complementarmente, por meio das resoluções CONAMA 302 e 303, reconhece-se institucionalmente a importância multifuncional das APPs na propriedade rural, que se tornam essenciais dentro de suas interações ecossistêmicas (Brasil, 2002a; 2002b). Segundo Silva et al. (2011), algumas funções ambientais das APPs são o condicionamento do solo para o amortecimento do escoamento pluvial; a regularização hidrológica, reduzindo efeitos de erosão, enxurradas, deslizamento e escorregamento de massa em ambientes urbanos e rurais; a proteção e manutenção da biodiversidade local; onde ocorrem altos graus de especialização e endemismo, além da manutenção da população de polinizadores e de ictiofauna. Como afirma Pereira (2012), a Lei Federal $n^{\circ} 4.771 / 65$ por vezes gerou dúvidas e equívocos de interpretação quanto ao seu conteúdo, cabendo ao Poder Público essa tarefa. Isso, aliado (i) ao desenvolvimento e aperfeiçoamento de estudos específicos sobre a temática; (ii) a constante transformação histórica da interação do homem com os recursos naturais; (iii) a conseguinte alteração da percepção destes recursos pelas populações e (vi) a necessidade de esclarecimentos dos parâmetros e definições dispostos na lei, promoveram diversas alterações e complementações na Lei Federal $\mathrm{n}^{\circ}$ 4.771/65, além da inserção de novas restrições e parâmetros anteriormente não contemplados em seu texto. Em 12 de maio de 2012, após extensas argumentações e discussões entre diversos setores da sociedade, caracterizando um debate maniqueísta entre os denominados "ambientalistas" e "ruralistas", foi aprovada no Congresso Nacional a Lei Federal $n^{\circ} 12.651 / 12$ (Brasil, 2012a). Conjuntamente foi publicada a Medida Provisória $\mathrm{n}^{\circ} 571 / 12$ com a finalidade de suprir lacunas dos vetos de determinadas passagens e artigos pelo Poder Executivo, e inserir outras inclusões na referida Lei (Brasil, 
2012b). A definição de APP dada pela Lei Federal $n^{\circ} 12.651 / 12$ traz como áreas de extrema importância para a dinâmica dos recursos naturais, através de diferentes enfoques. O texto legal suscitou questionamentos sobre a sustentabilidade das alterações, o que do ponto de vista dos ambientalistas seria um possível retrocesso na legislação ambiental brasileira, reconhecida mundialmente como uma das mais desenvolvidas. Já pelo lado dos ruralistas, ele foi importante para diminuir o passivo ambiental histórico no meio rural (Soares Filho, 2013). Muitas especificidades da Lei Federal $\mathrm{n}^{\circ} 12.651 / 12$ remete ao tamanho da propriedade, delimitado em função de uma medida agrária usada no Brasil, o Módulo Fiscal Brasileiro. Instituída pela Lei $\mathrm{n}^{\circ}$ 6.746/79, o MFB varia por município, entre 5 a 110 hectares (INCRA, 1980). Seu tamanho leva em conta o tipo de exploração predominante no município; a renda obtida com a exploração predominante; outras explorações existentes no município que, embora não predominantes, sejam expressivas em função da renda ou da área utilizada.

Nesse contexto, o objetivo deste trabalho foi avaliar os reflexos da Lei Federal $\mathrm{n}^{\circ}$ 12.651/12 em alguns tipos de Áreas de Preservação Permanente, em comparação com a da Lei Federal $n^{\circ}$ 4.771/65 e Resoluções CONAMA 302 e 303, em duas propriedades rurais localizadas nos Municípios de Itu e Sarapuí, ambas no Estado de São Paulo.

\section{MATERIAL E MÉTODOS}

As propriedades rurais do presente estudo localizam-se no município de Itu, no Bairro Taquaral, com 649,50 hectares (54,1 Módulos Fiscais), e no município de Sarapuí, no Bairro da Floresta, com 189,48 hectares (9,5 Módulos Fiscais), ambas no Estado de São Paulo, sob as respectivas coordenadas geográficas centrais $23^{\circ} 20^{\prime} 34^{\prime \prime} \mathrm{S}$ e $47^{\circ} 21^{\prime} 37^{\prime \prime} \mathrm{O}$; e $23^{\circ} 35^{\prime} 15^{\prime \prime} \mathrm{S}$ e 4746'03"O, em uma região de transição de Savana (Cerrado) e Floresta Ombrófila Densa (FAPESP, 2008). Os textos legais utilizados foram a Lei Federal $\mathrm{n}^{\circ} 4.771 / 65$ e as Resoluções CONAMA 302 e 303, conjuntamente tratadas neste trabalho como "Código anterior", e a Lei Federal $n^{\circ} 12.651 / 12$, referida como "Código atual". Além disso, trabalhos científicos sobre a temática acrescentaram raciocínios e argumentações para as discussões. As áreas e questões pertinentes a Reserva Legal ou Áreas de Uso Restrito não foram consideradas nesse trabalho, sendo tratadas apenas as APPs relacionadas a cursos e reservatórios de água e a nascentes, intermitentes e perenes. Esses elementos da paisagem foram identificados a partir de curvas de nível vetorizadas de Cartas Topográficas do Instituto de Geografia e Cartografia (IGC), em escala de 1:10.000 (cursos de água e nascentes) e ortofoto georeferenciada do ano 2005, em escala de 1:30.000 (reservatórios de água). A identificação de áreas consolidadas em APPs, conforme definição da Lei Federal $\mathrm{n}^{\circ} 12.651 / 12$, foi realizada a partir da ortofoto supracitada, com auxilio de receptores de sinais do Sistema de Posicionamento Global, imagens orbitais do Google Earth ${ }^{\circledR}$ e checagens de campo. Os limites das propriedades foram obtidos em Plantas Topográficas elaboradas segundo Norma Técnica para Georreferenciamento de Imóveis Rurais do Instituto Nacional de Colonização e Reforma Agrária (Brasil, 2010). A partir dos cursos e reservatórios de água, nascentes e áreas consolidadas identificadas, as respectivas faixas de APPs foram delimitadas utilizando-se técnicas de geoprocessamento digital no software AutoCad® versão 2011. Utilizou-se o comando offset, para gerar as distâncias de APPs em relação aos cursos hídricos, nascentes e reservatórios artificiais d'água, considerando suas respectivas distâncias especificadas no Código anterior e no Código atual, e os comandos trim e join para fracionar os excessos e sobreposições das linhas geradas, unir os elementos de interesse e converter as feições em polígonos, a partir dos quais foram quantificadas as áreas de APPs. Foi considerado que não há variação sazonal do leito dos cursos de água. 


\section{RESULTADOS E DISCUSSÃO}

Na propriedade de Itu, contabilizadas com o Código anterior as APPs somaram 20,97\% da área total do imóvel, quando considerado o Código atual esse valor reduziu-se para 17,81\% (Tabela 1 e Figura 1). Já na propriedade de Sarapuí, de acordo com o Código anterior, as APPs representavam $23,16 \%$ da área total do imóvel, reduzindo-se para apenas $8,11 \%$ quando considerado o Código atual.

Tabela 1. Áreas de APP para as propriedades de Itu e Sarapuí, SP, conforme o Código Florestal anterior e o Código Florestal atual.

\begin{tabular}{lcccc}
\hline Propriedade & $\begin{array}{c}\text { APP segundo o } \\
\text { Código anterior } \\
\text { Co------------------------ }\end{array}$ & $\begin{array}{c}\text { APP segundo o } \\
\text { Código atual }\end{array}$ & \multicolumn{2}{c}{ Diferença } \\
\hline Itu & 136,23 & 115,69 & 20,54 & \% \\
Sarapuí & 43,89 & 28,52 & 15,36 & $-35,00$ \\
\hline
\end{tabular}

Embora aparentemente os percentuais pareçam pequenos, a redução da área legalmente protegida torna vulneráveis as áreas úmidas adjacentes aos recursos hídricos, provedoras de muitos serviços ambientais (Borges et al., 2011; Meztger, 2010). Dentre eles citam-se a proteção dos recursos hídricos, através da contenção de erosões oriundas das forças das águas pluviais em escoamento superficial e da dissipação de seu potencial erosivo; e o fornecimento de alimento, abrigo e ambiente de reprodução para muitas espécies (Silva et al., 2011). Um ponto relevante do Código atual foi a alteração do referencial para início da demarcação da faixa de APP, originalmente do nível mais elevado do leito sazonal do curso d'água para a borda da calha do leito regular. Em uma análise técnica, poder-se-ia inferir que a APP é atualmente locada no que se entende ser o próprio corpo d'água, nas áreas de planícies de inundação, conhecidas também como várzeas, as quais deixam de estar protegidas em sua plenitude. No presente estudo, foi desconsiderada a variação sazonal no leito dos cursos d'água em ambas as propriedades, o que não altera as respectivas faixas de APP. Entretanto, é oportuno ressaltar que o Rio Sarapuí, que atravessa a propriedade de mesmo nome, apresenta fortes alterações em seu curso, condicionado pela variação de altitude e topografia na região, o que possibilita a formação destas planícies de inundação (Figura 1).

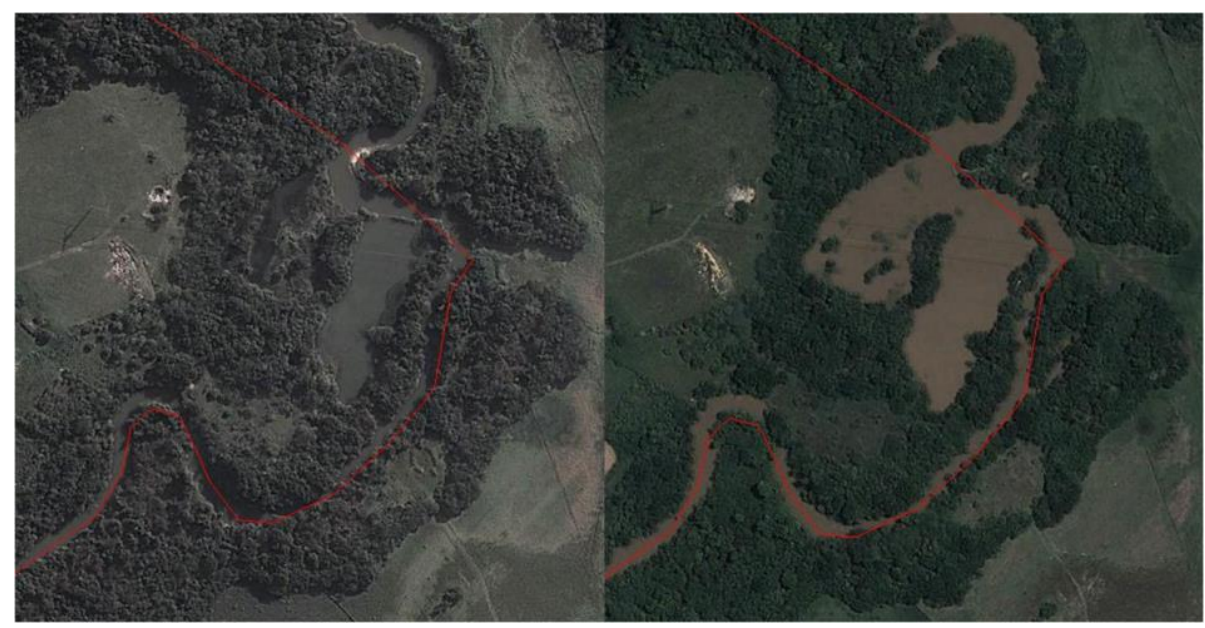

Figura 1. Imagens orbitais do lago artificial no limite da propriedade em Sarapuí, SP, em outubro de 2011, período seco (à esquerda) e em julho de 2012, período chuvoso (à direita). Detalhe para a linha em vermelho com a divisa de propriedade do imóvel.

Fonte: Adaptado de GOOGLE EARTH. Localização. Disponível em: <https://goo.gl/maps/IswOb>. Acesso em: 21 jul. 2014. 
Para Ramos e Tosi (2012), o corpo d'água não pode ser entendido somente como o leito regular onde as águas costumam fluir, pois este varia sazonalmente em função das chuvas. Essa alteração do referencial para início da demarcação da faixa de APP em cursos d'água pode propiciar uma desregulação na dinâmica dos elementos inerentes ao ecossistema envolto nos cursos d'água. Como exemplo, a redução das trocas de material inerte depositado no leito do rio nas épocas de estiagem na produção ictíca (Lewhinsohn et al., 2010).

Como pode ser observado na Tabela 2 e Figura 2, o curso d'água foi o elemento de hidrografia que mais influenciou a redução nas áreas de APPs, responsável isoladamente por mais de $80 \%$ na propriedade de Sarapuí.

Tabela 2. Valores da redução na faixa de Áreas de Preservação Permanente para as propriedades de Sarapuí, SP, de acordo com o tipo de elemento da hidrografia relacionado, considerando o cálculo pelo Código anterior e atual.

\begin{tabular}{lcr}
\hline \multicolumn{1}{c}{ Elemento da Hidrografia } & \multicolumn{2}{c}{ Redução nas APPs } \\
& ha & \multicolumn{1}{c}{$\%$} \\
\hline Reservatório Artificial & 0,52 & 3,40 \\
Nascente & 2,31 & 15,04 \\
Curso d'água & 12,53 & 81,57 \\
\hline Total & $\mathbf{1 5 , 3 6}$ & $\mathbf{1 0 0 , 0 0}$ \\
\hline
\end{tabular}

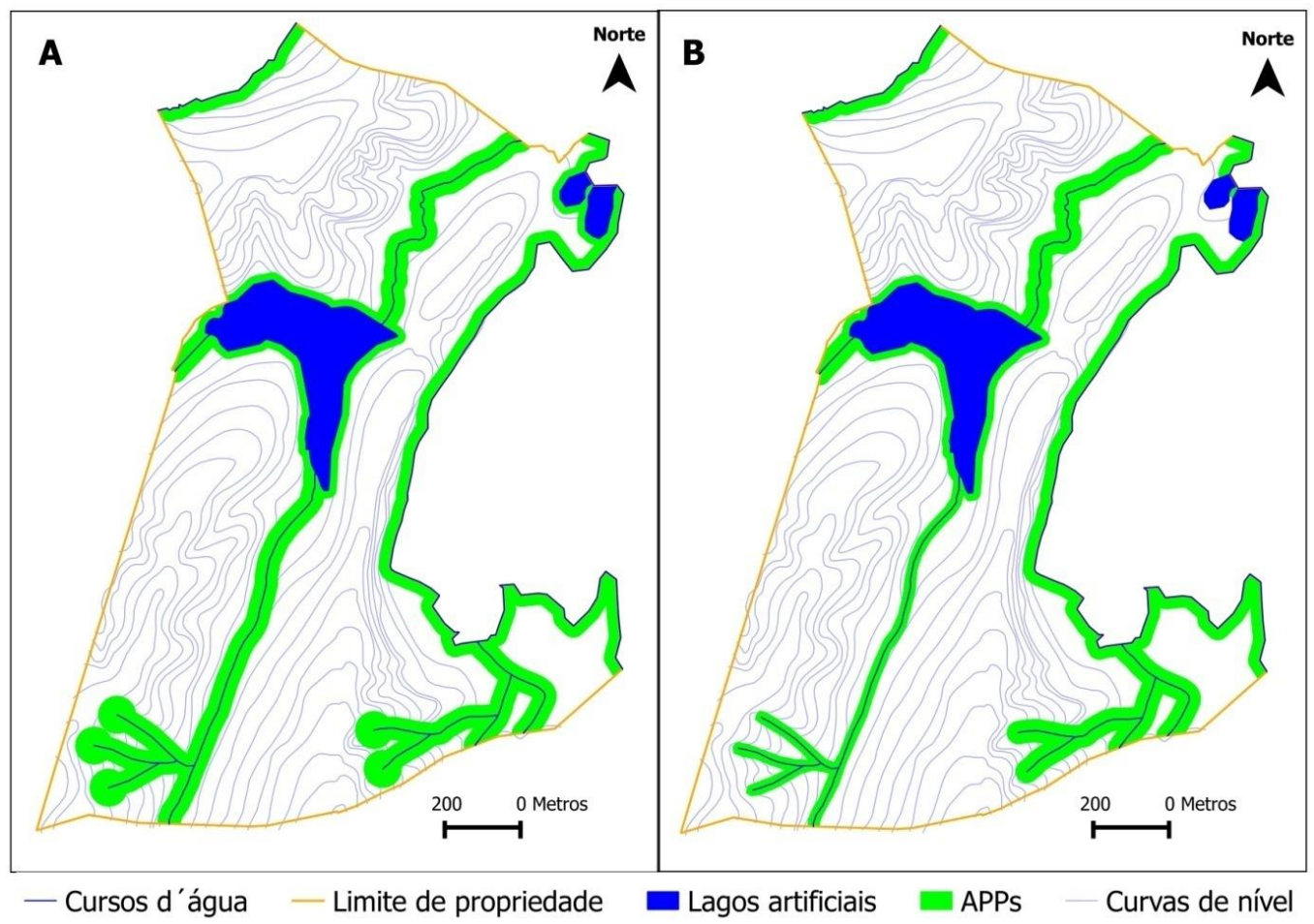

Figura 2. Elementos de hidrografia e Áreas de Preservação Permanente (APPs) para a propriedade de Sarapuí, SP, conforme o Código anterior (A) e o Código atual (B).

Em estudo de mesmo teor em uma propriedade rural com 50,29 hectares no Município de Erechim, RS, Cuppini et al. (2012) verificaram redução de 4,56 hectares em áreas de APPs, o que representou $9,07 \%$ da área total da propriedade. Segundo os autores, a propriedade possuía 25,04\% (12,59 hectares) de áreas de preservação permanente de acordo com Código antigo, em contraposição a valores menos expressivos conforme o Código atual, onde as 
APPs representaram 15,97\% da área da propriedade (8,03 hectares). Respeitadas as devidas situações, esta variação é semelhante à observada no imóvel de Sarapuí, onde pouco mais de um terço das APPs deixaram de existir legalmente. Para a propriedade em Sarapuí, a redução nas áreas de APPs foi influenciada, principalmente, pelo Artigo n61-A do Código atual, onde fica autorizada a continuidade de atividades agrossilvipastoris, de ecoturismo e de turismo rural em áreas consolidadas até 22 de julho de 2008. Tal estratégia dos legisladores teve o intuito de diminuir o passivo ambiental em propriedades rurais brasileiras, já que o Decreto Federal $\mathrm{n}^{\circ}$ 6.514/08 dispõe sobre as infrações e sanções administrativas ao meio ambiente, estabelecendo processo administrativo federal para apuração destas infrações, dentre outras providencias (Brasil, 2008).

Para a propriedade em Itu não houve variação das faixas de preservação permanente no entorno dos cursos d'água, sendo que 45,96\% da redução nas áreas de APPs (9,44 hectares) ocorreram no entorno das nascentes intermitentes, já que esses locais estão dispensados de manter APP em seu entorno segundo o Código atual (Tabela 3 e Figura 3). Nessa propriedade, somente três nascentes são perenes de acordo com informações da carta do IGC, e os $54,04 \%$ restantes $(11,10$ hectares) são correspondentes a faixas de APP no entorno dos reservatórios artificiais, conforme o Código anterior.

Tabela 3. Valores da variação na faixa de APP observada no imóvel em Itu/SP de acordo com o tipo de elemento da hidrografia relacionado.

\begin{tabular}{lcr}
\hline \multirow{2}{*}{ Elemento da Hidrografia } & \multicolumn{2}{c}{ Redução nas APPs } \\
& ha & \multicolumn{1}{c}{$\%$} \\
\hline Nascente & 9,44 & 45,96 \\
Cursos d'água & 0,00 & 0,00 \\
Reservatório Artificial & 11,10 & 54,04 \\
\hline Total & 20,54 & 100,00 \\
\hline
\end{tabular}

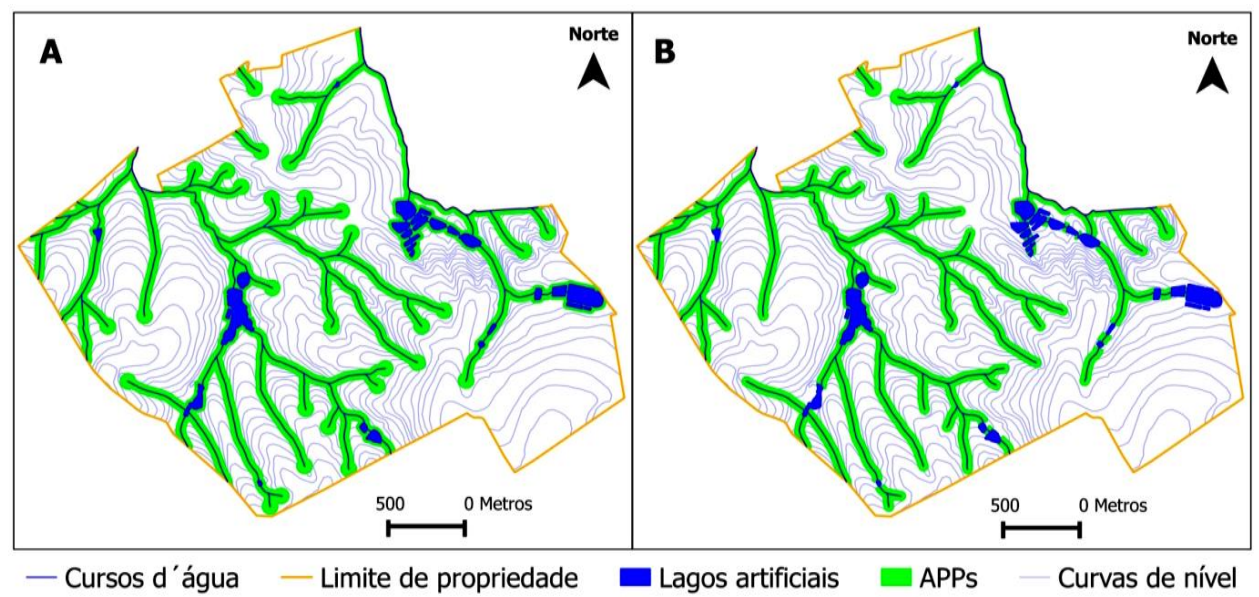

Figura 3. Elementos de hidrografia e Áreas de Preservação Permanente (APPs) para a propriedade de Itu, SP, conforme o Código anterior (A) e o Código atual (B).

Para a propriedade de Itu, somente dois reservatórios de um total de trinta e três possuem superfície acima de um hectare, portanto os únicos a manter mesma faixa de preservação nas duas situações, já que o código atual dispensa a manutenção de APP nesses casos. Para a propriedade de Itu, foi detectado que a redução da APP conforme a disposição no Código atual acabou por fragmentar as faixas de APP na propriedade de devido à presença de 
reservatórios de água com menos de um hectare de superfície (vide Figura 3). Do ponto de vista da qualidade ambiental, como autossuficiência da regeneração natural e manutenção da biodiversidade, essa fragmentação é prejudicial porque os corredores ecológicos formados pelas APPs são elementos de interligação dos fragmentos remanescentes na paisagem (Gonçalves et al., 2012). A dispersão de pólen e sementes também é prejudicada pela descontinuidade da vegetação natural. Na propriedade avaliada por Cuppini et al. (2012), o fator determinante para a redução de APPs foi a redução da faixa de APP de cursos d'água em áreas consolidadas para o mínimo de 8 metros (rio inferior a 10 metros de largura), em detrimento a faixa de 30 metros do Código anterior. O autor infere ainda que estas alterações trouxeram uma maior área agricultável ao proprietário do imóvel, porém com uma tendência maior de fragmentação das APPs ao utilizar o critério tamanho do imóvel para estabelecimento das faixas de preservação.

De acordo com Sauer e França (2012), a maior parte das alterações ocorridas com a mudança do Código Florestal Brasileiro, seja partindo da afirmação do direito absoluto de propriedade ou da necessidade de produzir alimentos, têm como propósito o uso ilegal de áreas que deveriam ser conservadas ou preservadas como vistas a sustentabilidade no meio rural. Para os autores, isso representa riscos reais à biodiversidade brasileira e a tentativa de criar uma lei baseada em incentivos e não em comando e controle, acabando por ameaçar uma suposta lógica conservacionista. Loubet e Almeida (2012) esclarecem que, sobre a recuperação das APPs e RLs, não há questionamentos de que este é um direito subjetivo ambiental, assegurado pela Constituição Federal do Brasil (Artigo 225) o direito ao meio ambiente ecologicamente equilibrado (Brasil, 1988). Assim sendo, um direito garantido por lei não pode ser restringido por legislações posteriores. Segundo os autores, o retrocesso socioambiental não pode ser tolerado porque põe em risco a proteção dos direitos da sociedade frente às alterações na legislação, bem como a efetividade constitucional. Considerando que é um direito da população dispor de recursos naturais preservados, e que as faixas de APP determinadas anteriormente asseguravam a proteção dos recursos naturais de uma forma mais restritiva, diversas alterações trazidas pela Lei Federal $\mathrm{n}^{\mathbf{0}}$ 12.561/12 mostram-se tecnicamente incoerentes. Entretanto, deve-se considerar que os proprietários rurais não podem arcar isoladamente com o ônus da conservação ambiental no meio rural, em detrimento da geração de trabalho e renda em suas propriedades (Araújo e Valle, 2013).

Nesse trabalho, foram observadas diminuições nas áreas de APP de cursos d'água, reservatórios artificiais d'água e nascentes considerando a recente alteração do Código Florestal Brasileiro. O elemento de maior influência nessa variação foi a alteração da faixa de preservação estabelecida ao longo dos cursos d'água onde existam áreas em preservação permanente com atividades consolidadas até 22 de julho de 2008, com destaque ao imóvel de Sarapuí. A redução de APP nas nascentes, consideradas apenas as perenes, também foi elevada no entorno de reservatórios artificiais de água na propriedade de Itu. Com isto, as nascentes intermitentes deixam de ter proteção legal, resultando em menor proteção do recurso hídrico, visto que as nascentes são responsáveis pela manutenção da vazão e por alimentar o fluxo dos cursos d'água de outros elementos. Das práticas a serem tomadas pelos proprietários rurais, é importante considerar que todo imóvel rural deve ser cadastrado no Cadastro Ambiental Rural (CAR) (Brasil, 2012b), dispositivo legal que, associado às ferramentas de SIG, pode ser capaz de proporcionar o monitoramento constante e efetivo da situação ambiental das propriedades rurais, com a possibilidade de adoção de práticas eficazes no que tange a gestão ambiental (Brasil, 2012a; Miranda, 2012).

\section{CONCLUSÕES}

As recentes modificações no Código Florestal Brasileiro reduziram as APPs de alguns elementos da paisagem nas duas propriedades avaliadas. Também houve fragmentação da 
APP no entrono de cursos d'água em uma propriedade analisada. De modo geral, os fatores que mais contribuíram para esse resultado foram (i) a diminuição na largura estabelecida para APPs de cursos de água em áreas consolidadas e (ii) a dispensa de estabelecimento de APP em nascentes intermitentes e no entorno de lagos artificiais com superfície inferior a um hectare. Ressalta-se que devido ao caráter quantitativo desse trabalho, são necessários estudos mais detalhados quanto aos aspectos qualitativos da redução da APPs e suas interações com outros elementos da paisagem, como a fauna, flora e atividades antrópicas.

\section{REFERÊNCIAS}

ARAÚJO, F. C. de; VALLE, R. S. T. do (Org.) Política agrícola como vetor para a conservação ambiental. São Paulo: Instituto Socioambiental, 2013. 46p. Disponível em: 〈http://www.socioambiental.org/sites/blog.socioambiental.org/files/publicacoes/pol_agricola.pdf〉 . Acesso em: 08 jun. 2013.

BORGES, L. A. C.; REZENDE, J. L. P. de; PEREIRA, J. A. A.; COELHO JÚNIOR, L. M. D.; BARROS, A. de. Áreas de preservação permanente na legislação ambiental brasileira. Ciência Rural, Santa Maria, v. 41, n. 7, p. 1202-1210, jul. 2011. http://dx.doi.org/10.1590/S0103-84782011000700016

BRASIL. Decreto no 23.793, de 23 de janeiro de 1934. Aprova o código florestal que com este baixa. Disponível em: <http://www.planalto.gov.br/ccivil_03/decreto/1930-1949/D23793.htm>. Acesso em: 02 fev. 2014.

BRASIL. Lei no 4.771, de 15 de setembro de 1965. Institui o novo Código Florestal. Disponível em: <http://www.planalto.gov.br/ccivil_03/leis/14771.htm>. Acesso em: 15 fev. 2014.

BRASIL. Constituição da República Federativa do Brasil de 1988 . Disponível em: <http://www.planalto.gov.br/ccivil_03/constituicao/constituicaocompilado.htm〉. Acesso em: 08 jun. 2013.

BRASIL. Decreto Federal no 6.514, de 22 de julho de 2008. Dispõe sobre as infrações e sanções administrativas ao meio ambiente, estabelece o processo administrativo federal para apuração destas infrações, e dá outras providências. Disponível em:<http://www.planalto.gov.br/ccivil_03/_ato20072010/2008/ decreto/D6514.htm>. Acesso em: 08 jun. 2013.

BRASIL. Ministério do Desenvolvimento Agrário. Instituto Nacional de Colonização e Reforma Agrária. Norma Técnica para Georreferenciamento de Imóveis Rurais. Aplicada à Lei 10.267, de 28 de agosto de 2001 e do Decreto 4.449, de 30 de outubro de 2002. $2^{\mathrm{a}}$ ed. Brasília, 2010. 86p. Disponível em: <http://200.252.80.40/Credencia/ download/Norma_Tecnica.pdf>. Acesso em: 25 jun. 2014.

BRASIL. Lei Federal no 12.651, de 25 de maio de 2012a. Dispõe sobre a proteção da vegetação nativa; altera as Leis n6.938, de 31 de agosto de 1981, 9.393, de 19 de dezembro de 1996, e 11.428, de 22 de dezembro de 2006; revoga as Leis $n^{\circ} 4.771$, de 15 de setembro de 1965, e 7.754, de 14 de abril de 1989, e a Medida Provisória ${ }^{\circ}$ 2.166-67, de 24 de agosto de 2001; e dá outras providências. Disponível em: <http://www.planalto.gov.br/ccivil_03/_ato2011-2014/2012/lei/112651.htm>. Acesso em: 20 fev. 2014.

BRASIL. Medida Provisória no 571, de 25 de maio de 2012b. Altera a Lei no 12.651, de 25 de maio de 2012, que dispõe sobre a proteção da vegetação nativa; altera as Leis nos 6.938, de 31 de agosto de 1981, 9.393, de 19 de dezembro de 1996, e 11.428, de 22 de dezembro de 2006; revoga as Leis nos 4.771, de 15 de setembro de 1965, e 7.754, de 14 de abril de 1989, e a Medida Provisória no 2.166-67, de 24 de agosto de 2001. Disponível em: <http://www.planalto.gov.br/ccivil_03/_ato20112014/2012/Mpv/571.htm>. Acesso em: 05 fev. 2014. 
BRASIL. Decreto no 7.830, de 17 de outubro de 2012c. Dispõe sobre o Sistema de Cadastro Ambiental Rural, o Cadastro Ambiental Rural, estabelece normas de caráter geral aos Programas de Regularização Ambiental, de que trata a Lei no 12.651, de 25 de maio de 2012, e dá outras providências. Disponível em: <http://www.planalto.gov.br/ccivil_03/_Ato2011-2014/2012/Decreto /D7830.htm>. Acesso em: 15 fev. 2014.

BRASIL. Conselho Nacional de Meio Ambiente - CONAMA. Resolução CONAMA no 303, de 20 de março de 2002a. Dispõe sobre parâmetros, definições e limites de Áreas de Preservação Permanente. Disponível em: <http://www.mma.gov.br/port/conama/res/res02/res30302.html〉. Acesso em: 15 fev. 2014.

BRASIL. Conselho Nacional do Meio Ambiente - CONAMA. Resolução CONAMA no 302, de 20 de março de 2002b. Dispõe sobre os parâmetros, definições e limites de Áreas de Preservação Permanente de reservatórios artificiais e o regime de uso do entorno. Disponível em: <http://www.mma.gov.br/port/conama/res/res02/res30202.html>. Acesso em: 15 fev. 2014.

CUPPINI, D. M.; DECIAN, V.; ROVANI, I. L.; DE QUADROS, F. R.; ZOTTI, N. C. Análise das áreas de preservação permanente em uma propriedade rural sob o enfoque do Código Florestal Federal (Brasil 1965) e Lei 12.727/2012. Perspectiva, Erechim, v. 36, n. 135, p. 41-45, set. 2012.

FUNDAÇÃO DE AMPARO À PESQUISA DO ESTADO DE SÃO PAULO - FAPESP. Conhecimento e uso sustentável da biodiversidade brasileira: o Programa BiotaFAPESP/ Fundação de Amparo à Pesquisa do Estado de São Paulo. São Paulo: FAPESP, 2008. 204 p.

GARCIA, Y. M. O Código Florestal Brasileiro e suas alterações no Congresso Nacional. Geografia em Atos, Presidente Prudente, v. 1, n. 12, p. 54-74, jan-jun. 2012.

GONÇALVES, A. B.; MARCATTI, G. E.; RIBEIRO, C. A. A. S.; SOARES, V. P.; MEIRA NETO, J. A. A.; LEITE, H. G. et al. Mapeamento das áreas de preservação permanente e identificação dos conflitos de uso da terra na sub-bacia hidrográfica do rio camapuãalbrumado. Revista Árvore, Viçosa-MG, v. 36, n. 4, p. 759-766, 2012. http://dx.doi.org/10.1590/S0100-67622012000400017

INSTITUTO NACIONAL DE COLONIZAÇÃO E REFORMA AGRÁRIA - INCRA (Brasil). Instrução Especial/INCRA no 20, de 28 de maio de 1980. Estabelece o módulo fiscal de cada município, previsto no Decreto n84.685 de 06 de maio de 1980. Aprovado pela Portaria/MA 146/80. Diário Oficial [da] União, Brasília, 12 jun. 1980, Seção I, p. 11.606, 1980. Disponível em: $<$ http://www.incra.gov.br/index.php/institucionall/legislacao--/atos-internos/instrucoes/file/129instrucao-especial-n-20-28051980>. Acesso 03 jun. 2013.

LEWHINSON, T. M.; METZGER, J. P.; JOLY, C. A.; CASATTI, L.; RODRIGUES, R. R.; MARTINELLI, L. A. Impactos potenciais das alterações propostas para o Código Florestal Brasileiro na biodiversidade e nos serviços ecossistêmicos: documentosíntese produzido por Pesquisadores do PROGRAMA BIOTA-FAPESP e pela ABECO (Associação Brasileira de Ciência Ecológica e Conservação). 2010. Disponível em: <http://www2.unesp.br/revista/wp-content/uploads/2010/10/Biota-Fapesp-ABECOSintese-CFB-e-biodiversidade.pdf >. Acesso em: 15 maio 2013.

LOUBET, L. F.; ALMEIDA, L. A. F. de Inconstitucionalidades dos retrocessos empreendidos pelo novo Código Florestal. 2012. Disponível em: $<$ http://jus.com.br/revista/texto/22582/inconstitucionalidades-dos-retrocessosempreendidos-pelo-novo-codigo-florestal >. Acesso em: 10 jun. 2013. 
METZGER, J. O Código Florestal tem base científica? Conservação e Natureza, Curitiba, PR, v. 8, n. 1, p. 92-99, 2010.

MIRANDA, C. R. de O Novo Código Florestal: principais modificações. 2012. 8 p. Disponível em: $<$ http://www.cnpsa.embrapa.br/filo/adm/anx/anx338Codigoflorestal.pdf >.Acesso em 03 jun. 2013.

PEREIRA, M. de P. A cidade como mercadoria: influências do setor privado na produção do espaço urbano. Revista de Ciências Humanas, Viçosa, v. 12, n. 2, p. 446-460, jul./dez. 2012.

RAMOS, R. I.; TOSI, I. Código Florestal: apreciação atualizada. Relatório da consultoria referente à apreciação atualizada do Código Florestal. São Paulo: ABES, 2012. Disponível em: <http://www.abes-sp.org.br/arquivos/atualizacao_codigo_florestal.pdf>. Acesso em: 08 jun. 2013.

SAUER, S.; FRANÇA, F. C. de Código Florestal, função socioambiental da terra e soberania alimentar. Caderno CRH, Salvador, v. 25, n. 65, p. 285-307, maio/ago. 2012.

SILVA, J. A. A. et al. O Código Florestal e a ciência: contribuições para o diálogo. São Paulo: SBPC; ABC, 2011. 124p. Disponível em: 〈http://www.abc.org.br/IMG/pdf/doc-547.pdf〉. Acesso em: 08 jun. 2013.

SOARES-FILHO, B. S. Impacto da revisão do Código Florestal: como viabilizar o grande desafio adiante? Brasília: Secretaria de Assuntos Estratégicos, 2013. Disponível em: <http://www.sae.gov.br/site/wp-content/uploads/Artigo-codigo-florestal.pdf>. Acesso em: 28 jun. 2014. 